\title{
Modeling the Effect of the Curing Conversion on the Dynamic Viscosity of Epoxy Resins Cured by an Anhydride Curing Agent
}

\author{
F. Teyssandier, ${ }^{1}$ M. Ivanković, ${ }^{2}$ B. J. Love ${ }^{1,3,4}$ \\ ${ }^{1}$ Department of Materials Science, University of Michigan, Ann Arbor, Michigan 48109 \\ ${ }^{2}$ Faculty of Chemical Engineering and Technology, University of Zagreb, Marulicev trg 19, PP 177, HR10001, \\ Zagreb, Croatia \\ ${ }^{3}$ Biomedical Engineering, University of Michigan, Ann Arbor, Michigan 48109 \\ ${ }^{4}$ Department of Biologic and Materials Sciences (Dentistry), University of Michigan, Ann Arbor, Michigan 48109
}

Received 27 August 2008; accepted 9 February 2009

DOI 10.1002/app.31148

Published online 7 October 2009 in Wiley InterScience (www.interscience.wiley.com).

\begin{abstract}
Published curing profiles of epoxy resins mixed with an anhydride curing agent and subsequently crosslinked were reanalyzed with a modified sigmoidal model to describe the dynamic viscosity accompanying resin curing. The sigmoidal analysis yielded two kinetic parameters, one relating to the induction time required to observe meaningful viscosity changes and one relating to the rate of viscosity rise in the rapidly polymerizing zone. Both of these kinetic factors decreased with increasing polymerization temperature. The analysis also led to the interpretation of the upper limit in viscosity in the model that correlated with a higher network density at higher temperatures. The initial viscosity was fixed in our model. The sigmoidal analysis led to a closer representation of the
\end{abstract}

dynamic viscosity data than the Williams-Landel-Ferry (WLF)-based analysis presented with the original data sets and, although from a more semiempirical basis, might be both easier and more adaptable for incorporating into other flow models. As a final observation, the induction time identified by the log-sigmoidal model correlated closely with the gelation time identified with a modifiedWLF-based model by Ivankovic et al. (J Appl Polym Sci 2003, 90, 3012); this suggested a similar activation energy threshold for curing advancement. (c) 2009 Wiley Periodicals, Inc. J Appl Polym Sci 115: 1671-1674, 2010

Key words: kinetics (polym.); modeling; rheology; thermosets

\section{INTRODUCTION}

There is an expanding body of experimental evidence linking dynamic viscosity data associated with polymerization to an array of molecular, kinetic, and purely empirical models for the prediction of flow in curing systems. These viscosity correlations have been used extensively to predict flow in adhesives and coatings, resin transfer molding, and resin infiltration for composites, where dynamic viscosity can be linked to flow fields, and voiding. ${ }^{1}$ The correlation of viscosity with chain length is also of critical fundamental importance within the polymer physics community, ${ }^{2-5}$ and it carries added importance related to the control of thermal runaway in bulk polymerization. ${ }^{6,7}$ For thermosets, the evolving network structure is a key feature in the regulation of continued flow, and there is interest in defining

Correspondence to: B. J. Love (bjlove@umich.edu).

Contract grant sponsor: Institut des Sciences et Techniques de l'Ingenieur de Lyon (through a fellowship to F.T.).

Journal of Applied Polymer Science, Vol. 115, 1671-1674 (2010) (C) 2009 Wiley Periodicals, Inc. the structure of the gel point both in terms of the physical structure and the corresponding viscosity. ${ }^{8,9}$ There are correlations between the rate of polymerization and the level of shrinkage arising in thermosets, although there seems to be some discussion about how much influence there is, at least for rapidly polymerizing mixtures. ${ }^{10-16}$

There has also been extensive effort to characterize the most appropriate mathematical models to describe transient viscosity of reactive thermosets. ${ }^{8}$ The current state of the art regarding different viscosity advancement models was presented by Halley and Mackay. ${ }^{17}$ The most easily and probably most extensively adapted models are based on $n$th order kinetics, where small molecule behavior is governed by one exponent and larger structures are governed by higher order exponents. ${ }^{18-24}$ The gel point is interpreted as a demarcation between small molecule and longer chain behavior, usually the inflection point in the dynamic viscosity ${ }^{23}$ or the maximum rate of viscosity rise. ${ }^{1}$ There are other interpretations of the gel point, including the crossover point between the storage modulus and loss modulus, ${ }^{25,26}$ the inflection point of the storage modulus, ${ }^{27}$ and the point at which the loss tangent is 
frequency-invariant ${ }^{28-30}$ according to dynamic mechanical spectroscopy. There are other nonlinear models based on other reactivity parameters, ${ }^{31,32}$ thermodynamic influences similar to the WilliamsLandel-Ferry (WLF) model, ${ }^{17}$ and semiempirical models to describe the time-dependent viscosity. ${ }^{17,24,33-35}$ The WLF-based chemorheological model used by Ivankovic et al. ${ }^{1}$ defined the conversion-dependent viscosity with temperature as:

$$
\eta(T, \alpha)=\eta_{g}\left[\frac{-C_{1}\left(T-T_{g 0}\right)}{C_{2}+T-T_{g 0}}\right]\left(\frac{\alpha_{g}}{\alpha_{g}-\alpha}\right)^{n}
$$

where $C_{1}$ and $C_{2}$ are WLF constants, $\eta_{g}$ is the viscosity at $T_{g}, T$ is the polymerization temperature, $T_{g 0}$ is the glass-transition temperature of the uncured resin, and $\alpha$ and $\alpha_{g}$ are the instantaneous conversion and the conversion at the gel point, respectively. Time is not explicitly identified here, but it is related to the conversion rate. What appears evident is that no one model is generic in its broad applicability across all polymerizing resins and monomers.

The initial success of the use of the sigmoidal chemorheological model for acrylate ${ }^{24,33}$ and epoxy conversion $^{35}$ led to interest in the further evaluation of its scope. The dynamic viscosity is related to time by the Boltzmann log-sigmoidal model:

$$
\log \eta(t)=\log \eta_{\infty}+\frac{\log \left(\eta_{0}\right)-\log \left(\eta_{\infty}\right)}{\left(1+e^{t-\frac{t t_{0}}{\Delta t}}\right)}
$$

where $\eta_{0}$ is the initial viscosity of the formulated resin; $\eta_{\infty}$ is tied to the viscosity approaching the torque limit in the rheometer as network formation evolves; $t_{0}$ is the induction time, corresponding to the time necessary for a change in the viscosity from $\log \eta_{0}$ to $\left(\log \eta_{0}+\log \eta_{\infty}\right) / 2$ and probably most closely associated with the gel time; $t$ is the time; and $\Delta t$ corresponds to the period associated with the sigmoidal transition region as the viscosity deviates from $\eta_{0}$ in the semilog linear regime. We chose to consider work by Ivankovic et al., ${ }_{1}$ who studied epoxy/anhydride curing kinetics accompanied by a WLF-based analysis for the dynamic viscosity rise.

In their original study, Ivankovic et al. ${ }^{1}$ used a bisphenol A epoxy resin (Ciba Geigy Araldite LY556) with an anhydride curing agent (HY918) and a heterocyclic amine accelerator (DY 070) in a 100/ 90/0.0.5 w/w mixture. ${ }^{1}$ Kruckenberg reported on the room-temperature viscosity of the Araldite epoxy resin as ranging between 9 and $12 \mathrm{~Pa} \mathrm{~s}^{36}$ and that of the curing agent was nominally $0.045 \mathrm{~Pa} \mathrm{~s}^{37}$ Typical activation energies for epoxy resin thinning due to thermal heating but insufficient for curing were on the order of $1.8 \mathrm{~kJ} / \mathrm{mol}^{38}$ The mixed resin was subsequently characterized by a range of thermal analy-

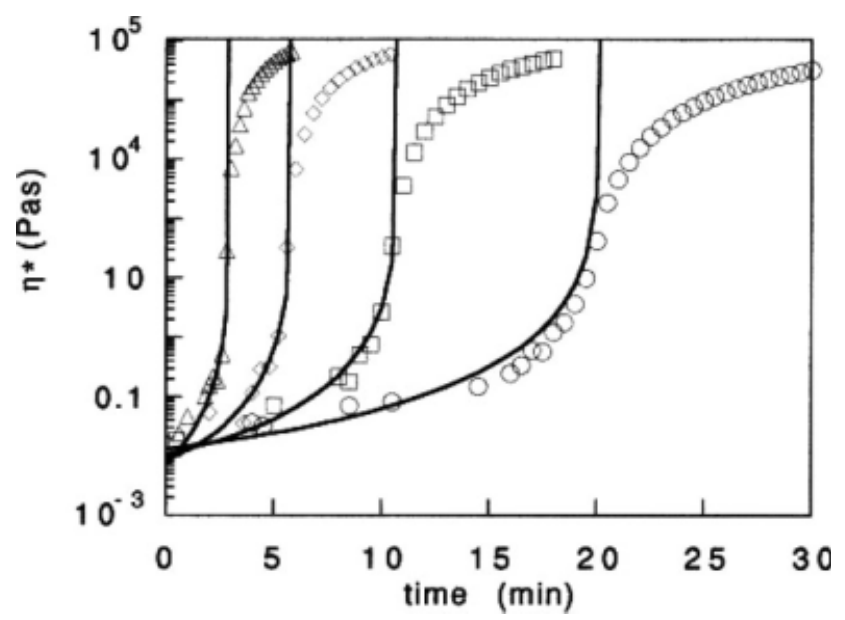

Figure 1 Complex viscosity $\left(\eta^{*}\right)$ and WLF-based prediction of the viscosity rise as a function of time for isothermal curing at $(\bigcirc) 110,(\square) 120,(\diamond) 130$, and $(\triangle) 140^{\circ} \mathrm{C}$ (data from Ivankovic et al. ${ }^{1}$ ).

sis tools, including rheology (Rheometrics RDS II rheometer) as a function isothermal curing, which ranged from 110 to $140^{\circ} \mathrm{C}$.

The rheology was characterized in parallel-plate mode with a gap height of $0.2 \mathrm{~mm}$. An angular frequency of $10 \mathrm{rad} / \mathrm{s}$ and an initial strain of $10 \%$ were applied. As curing proceeded, the strain was automatically adjusted to maintain the torque response within the range of the transducer. Resin flow measurements performed at $120^{\circ} \mathrm{C}$ over shear rates from 100 and $10 \mathrm{~s}^{-1}$ showed that it was independent of shear rate up to the gel point.

The published isothermal dynamic rheology data, which we were supplied, in the form of viscosity as functions of both time and temperature, were loaded into Origin ${ }^{\circledR}$ (Northampton, MA), a multifunctional mathematical analysis package, which has a sigmoidal fitting function. This allowed comparisons to be made between the originally published work and the alternative analysis. Two, three, and four variable log-sigmoidal analyses were performed as parameters for $\eta_{0}$ and $\eta_{\infty}$ were alternatively fixed to resolve their influence.

\section{RESULTS AND DISCUSSION}

The temperature-dependent dynamic viscosity $[\eta(t, T)]$ data from Ivankovic et al. ${ }^{1}$ are shown with the modified WLF-based chemorheology model predictions in Figure 1. Shown in Figure 2 are the model predictions based on eq. (2) with a fixed $\eta_{0}$. When we analyzed these results, we had immediate concern related to whether it was fair to use one specific initial viscosity value. Extrapolating from results of Shimazaki $^{38}$ to determine the thermal 


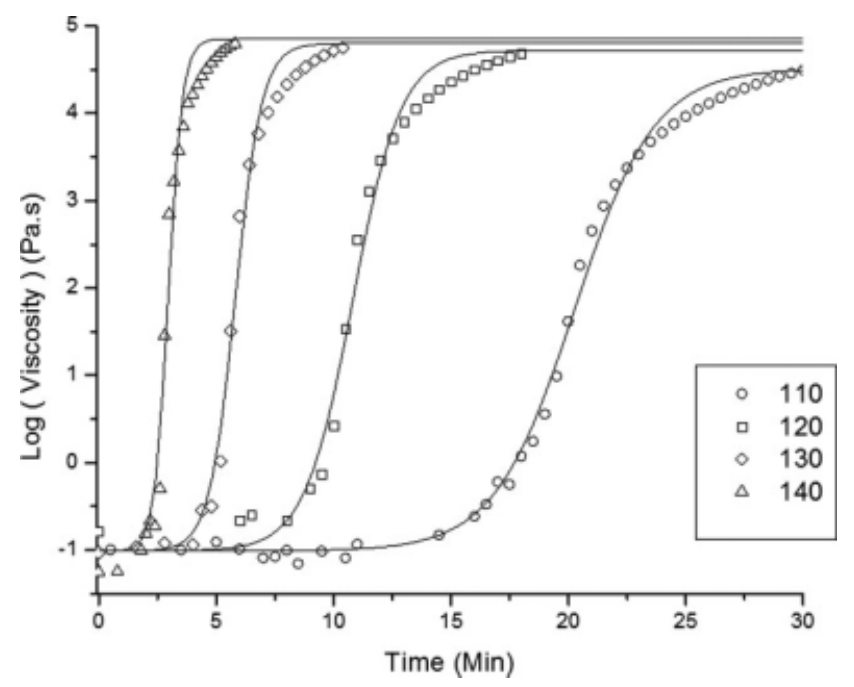

Figure 2 Data from Ivankovic et al. ${ }^{1}$ reanalyzed with (-) eq. (2).

dependence of epoxy/anhydride resin viscosity, we found that the variation in viscosity tracked with a trend in initial viscosity from about $7 \times 10^{-2} \mathrm{~Pa} \mathrm{~s}$ at $110^{\circ} \mathrm{C}$ to approximately $1.4 \times 10^{-2} \mathrm{~Pa} \mathrm{~s}$ at $140^{\circ} \mathrm{C}$. Additional characterization of the resin viscosity in the early stages of conversion would help to identify an appropriate initial viscosity. Either way, the interpretation of the initial viscosity appeared to be in the right range. Comparing the two models, we observed that the log-sigmoidal model predicted a wider array of dynamic viscosity for the epoxy anhydride system than the WLF-based model. Deviations were observed between the original WLF-based model with measurements beyond about $10^{3} \mathrm{~Pa} \mathrm{~s}$, and the dynamic viscosity was overpredicted. The log-sigmoidal model also overpredicted the viscosity but remained a viable model up to $10^{4} \mathrm{~Pa}$ s for all of the polymerization temperatures.

An increasing trend was found for the terminal $\eta_{\infty}$ with the temperature of curing $\left(T_{\text {cure }}\right)$ on the basis of the sigmoidal model in Figure 2. It is conceivable that there was a different terminal network density generated by the variation of $T_{\text {cure }}$ that could have affected $\eta_{\infty}$ in this model. Ivankovic et al. ${ }^{1}$ interpreted the gel time to correspond to the maximum in the second derivative of viscosity with time and used that to determine the fractional conversion at the gel point for each reaction temperature. Again comparing the sigmoidal analysis with the original work, we observed that the inflection time in the log-sigmoidal model $\left(t_{0}\right)$ corresponded closely with that of gelation time $\left(t_{\mathrm{gel}}\right)$ at approximately $33 \%$ conversion, ${ }^{1}$ as shown in Table I. Table I also shows the rest of the log-sigmoidal analysis parameters.

The initial viscosity for the isothermal experiments tended to a limit of approximately $0.1 \mathrm{~Pa} \mathrm{~s}$, which was fixed for all of the models. There can often be an observed dropoff in viscosity that occurs as the uncured resin senses a smaller activation energy at higher temperatures; this leads to a small dip in the viscosity before curing. ${ }^{39}$ This dropoff in viscosity before curing as the resin heated was not evident in the isothermal experiments, so perhaps the difference in curing agent between Seifi and Hojjati ${ }^{39}$ and Ivankovic et al. ${ }^{1}$ explains this difference.

Releasing the fixed constraints on $\eta_{0}$ and $\eta_{\infty}$ did not lead to any clear trends. The rheometer may have been less accurate because of the combination of the small torque required for $\eta_{0}$ and measurement in parallel-plate mode. Nevertheless, it appeared that the removal of the fixed constraint on the initial viscosity led to its determination ranging between $\log \eta_{0}=-1.21$ to -0.77 Pa s. There was a trend to higher terminal viscosity with increasing temperature. However, releasing the fixed constraint on the terminal viscosity led to its variation from log $\eta_{\infty}($ Pa s $)=4.51$ at $110^{\circ} \mathrm{C}$ to $\log \eta_{\infty}($ Pa s $)=4.82$ at $140^{\circ} \mathrm{C}$.

The log-sigmoidal reanalysis replicated the published dynamic viscosity for the epoxy-anhydride resin mixture as well as or better than the original WLF analysis. This observation was similar to those that we determined previously for other epoxies and acrylates. ${ }^{24,33,34}$ Prior work on polyurethanes has suggested that the log-sigmoidal model is not generic in describing viscosity advancement in all polymerizing resins. ${ }^{40}$

TABLE I

Comparison of the $t_{\text {gel }}$ Values Identified by the WLF-Based Model and the Two-Parameter Sigmoidal Model with the Initial Viscosity Fixed

\begin{tabular}{cccccc}
\hline$T_{\text {cure }}\left({ }^{\circ} \mathrm{C}\right)$ & $t_{\text {gel }}(\mathrm{min})^{\mathrm{a}}$ & $\begin{array}{c}t_{0} \text { from sigmoidal } \\
\text { analysis (min) }\end{array}$ & $\Delta t(\mathrm{~min})$ & $\log \eta_{0}($ Pa s $)$ & Log $\eta_{\infty}($ Pa s) \\
\hline 110 & 20.5 & 20.3 & 1.71 & -1.0 & 4.51 \\
120 & 11.0 & 10.81 & 1.02 & -1.0 & 4.72 \\
130 & 6.0 & 5.82 & 0.56 & -1.0 & 4.80 \\
140 & 3.3 & 2.96 & 0.30 & -1.0 & 4.85 \\
\hline
\end{tabular}

${ }^{\text {a }}$ Data from Ivankovic et al. ${ }^{1}$ 


\section{CONCLUSIONS}

A three-parameter log-sigmoidal analysis of epoxy anhydride dynamic viscosity led to similar determinations of the gel point compared with a WLF-based chemorheology model in a conceptually simpler way. The log-sigmoidal dynamic viscosity model replicated a larger zone of the dynamic spectrum and did not have such a significant deviation beyond the gel point. Although it is true that this phenomenological model may lack some physical features of a model more like the original WLFbased models, the log-sigmoidal model is easier to employ in modeling resin infiltration because fewer model parameters are required to make predictions. The normal features of smaller time constants associated higher curing rates were readily observed. $t_{0}$ corresponded very closely with the previously published $t_{\text {gel }}$ values, which suggested that if the goal of the model is to predict the curing time, the log-sigmoidal approach could be easier. Reducing the constraints on $\eta_{0}$ and $\eta_{\infty}$ did not lead to any additional insights into the chemorheology.

\section{References}

1. Ivankovic, M.; Incarnato, L.; Kenny, J. M.; Nicolais, L. J Appl Polym Sci 2003, 90, 3012.

2. Kamal, M. R. Polym Eng Sci 1974, 14, 231.

3. Kamal, M.; Sourour, S. Polym Eng Sci 1973, 13, 59.

4. Lipshitz, S. D.; Macosko, C. W. J Appl Polym Sci 1977, 21, 2029.

5. Lipshitz, S. D.; Macosko, C. W. Polym Eng Sci 1976, 16, 803.

6. Sangwai, J. S.; Saraf, D. N.; Gupta, S. K. Polymer 2006, 47, 3028 .

7. Sangwai, J. S.; Saraf, D. N.; Gupta, S. K. Rheol Acta 2007, 46, 455.

8. Achilias, D. S. Macromol Theory Simul 2007, 16, 319.

9. Achilias, D. S.; Kiparissides, C. Macromolecules 1992, 25, 3739.

10. Feng, L.; Suh, B. I. J Biomed Mater Res B 2006, 78, 63.

11. Feng, L.; Suh, B. I. J Biomed Mater Res B 2006, 76, 196.
12. Lu, H.; Stansbury, J. W.; Bowman, C. N. J Dent Res 2005, 84, 822.

13. Lu, H.; Stansbury, J. W.; Bowman, C. N. Dent Mater 2004, 20, 979.

14. Lu, H.; Stansbury, J. W.; Dickens, S. H.; Eichmiller, F. C.; Bowman, C. N. J Mater Sci: Mater Med 2004, 15, 1097.

15. Lu, H.; Stansbury, J. W.; Dickens, S. H.; Eichmiller, F. C.; Bowman, C. N. J Biomed Mater Res B 2004, 71, 206

16. Stansbury, J. W.; Trujillo-Lemon, M.; Lu, H.; Ding, X. Z.; Lin, Y.; Ge, J. H. Dent Mater 2005, 21, 56.

17. Halley, P. J.; Mackay, M. E. Polym Eng Sci 1996, 36, 593.

18. Sun, Y. Y.; Zhang, Z. Q.; Wong, C. P. IEEE Trans Components Packaging Technol 2006, 29, 190.

19. Sun, Y. Y.; Zhang, Z. Q.; Wong, C. P. Macromol Mater Eng 2005, 290, 1204

20. Cioffi, M.; Ganzeveld, K. J.; Hoffmann, A. C.; Janssen, L. Polym Eng Sci 2004, 44, 179.

21. Cioffi, M.; Ganzeveld, K. J.; Hoffmann, A. C.; Janssen, L. Polym Eng Sci 2002, 42, 2383.

22. Cioffi, M.; Hoffmann, A. C.; Janssen, L. Polym Eng Sci 2001, 41, 595.

23. Love, B. J.; Piguet-Ruinet, F. J Appl Polym Sci 2007, 106, 3605.

24. Love, B. J.; Piguet-Ruinet, F.; Teyssandier, F. J Polym Sci Part B: Polym Phys 2008, 46, 2319.

25. Haddadi, H.; Famili, M. H. N.; Nazokdast, E.; Moradi, S. Iran Polym J 2006, 15, 967.

26. Tung, C. Y. M.; Dynes, P. J. J Appl Polym Sci 1982, 27, 569.

27. Apicella, A.; Nicolais, L.; Iannone, M.; Passerini, P. J Appl Polym Sci 1984, 29, 2083.

28. Boey, F. Y. C.; Qiang, W. J Appl Polym Sci 2000, 76, 1248.

29. Winter, H. H. Polym Eng Sci 1987, 27, 1698.

30. Matejka, L. Polym Bull 1991, 26, 109.

31. Yang, Y. S.; Suspene, L. Polym Eng Sci 1991, 31, 321.

32. Malkin, A. Y.; Kulichikhin, S. G.; Kerber, M. L.; Gorbunova, I. Y.; Murashova, E. A. Polym Eng Sci 1997, 37, 1322.

33. Teyssandier, F.; Love, B. J. Eur Polym J, unpublished results.

34. Love, B. J.; Teyssandier, F.; Sun, Y. Y.; Wong, C. P. Macromol Mater Eng 2008, 293, 832

35. Teyssandier, F.; Sun, Y. Y.; Wong, C. P.; Love, B. J. Macromol Mater Eng 2008, 293, 828

36. Kruckenberg, T. M.; Paton, R. Resin Transfer Moulding for Aerospace Structures; Chapman \& Hall: London, 1998.

37. Dixie Chemical Co. MTHPA Product Specification Sheet, http://www.dixiechemical.com/specs/MTHPA.

38. Shimazaki, A. J Appl Polym Sci 1968, 12, 2013.

39. Seifi, R.; Hojjati, M. J Compos Mater 2005, 39, 1027.

40. Teyssandier, F.; Love, B. J Polym Eng Sci, to appear. 